$151 \cdot 20$

\title{
casa de baño, en Massachusetts
}

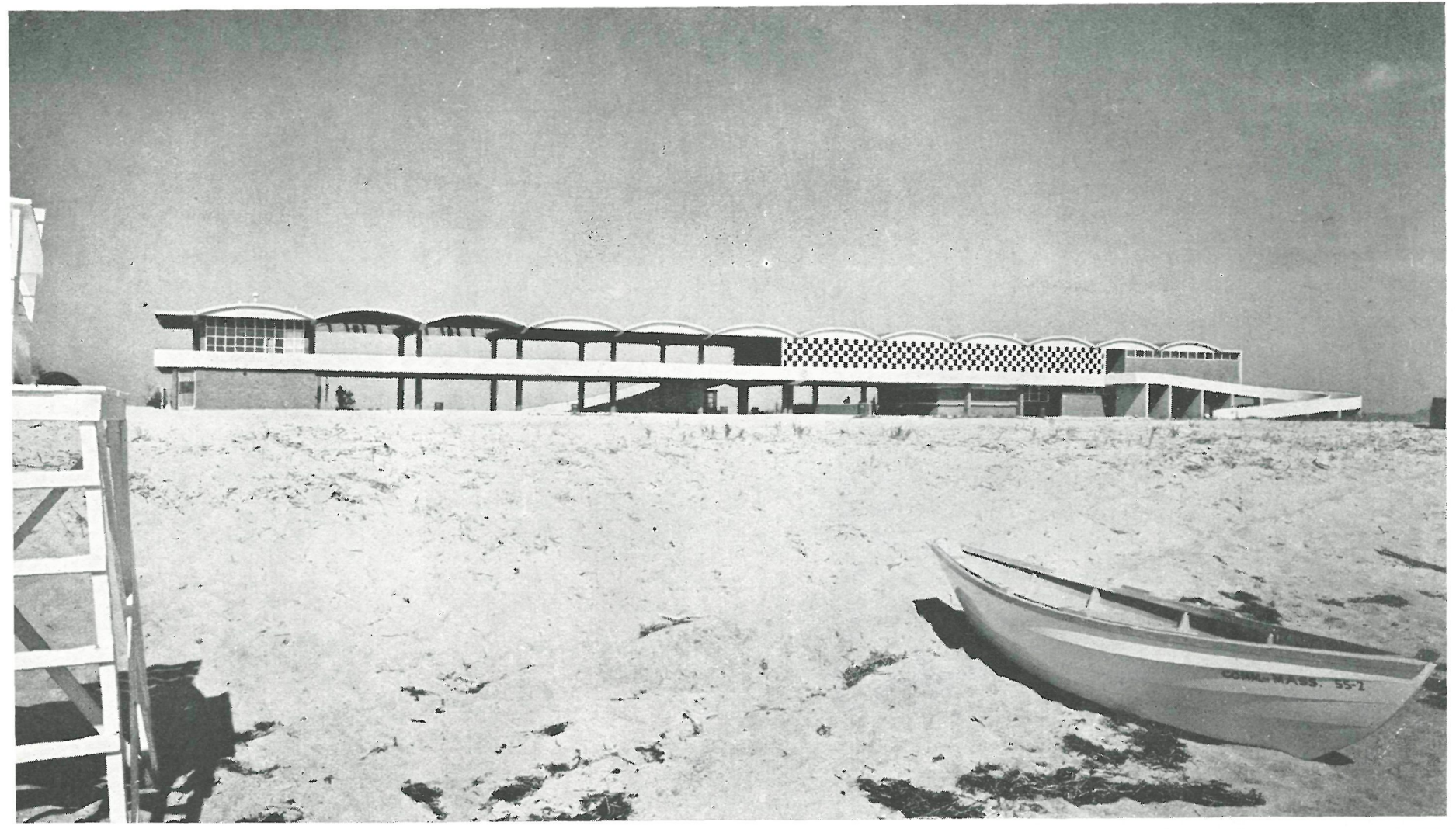

Este edificio corresponde a una serie de establecimientos semejantes, a lo largo de la costa del Atlántico, cuya realización se llevará a cabo sucesivamente. En el desarrollo del proyecto se ha tenido la máxima libertad, lo que ha dado lugar a la aparición de una construcción plástica transparente y de indudable belleza. En todo momento, se deja ver que la única misión que ha de cumplir es la de albergar los vestuarios de baño, disponiendo de los servicios necesarios, tales como: conserjería, aseos y parte administrativa.

Por esta razón, nada hay de espectacular, nada de aparatoso $y$, precisamente, en ello estriba la mejor condición del edificio que estamos reseñando: cumplir bien y formalmente con la misión pretendida.

Consta de dos plantas ubicadas en un bloque largo, cara al mar. En la planta baja, se han instalado: la cocina, un almacén, aseos para hombres y mujeres, equipo mecánico y sala de primeros auxilios sanitarios. En la primera planta, se distribuyen: la oficina general, vestuario para hombres y mujeres y la terraza; a este segundo nivel se accede por mediación de rampas y escaleras exteriores, que prestan movilidad al conjunto.

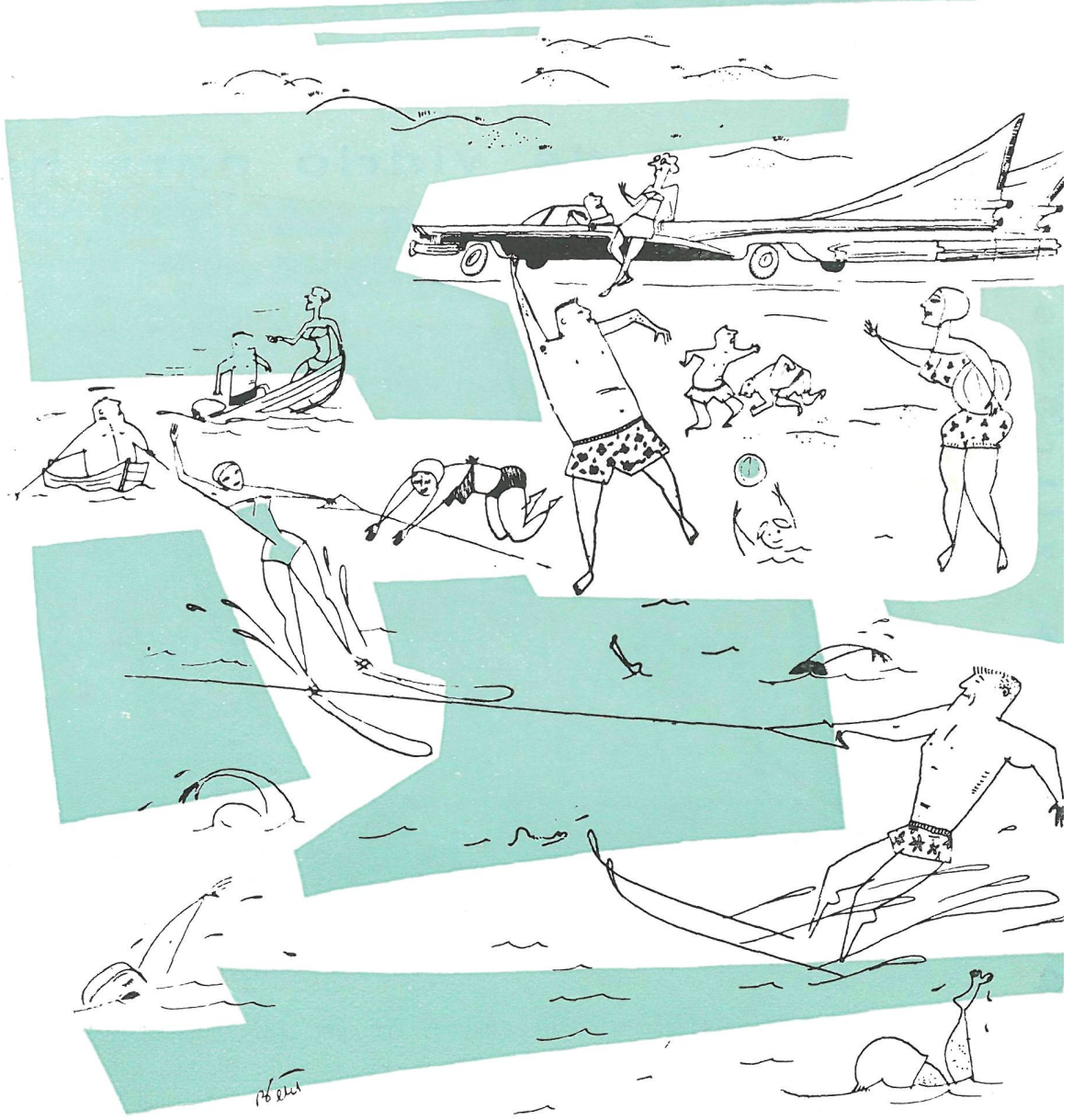



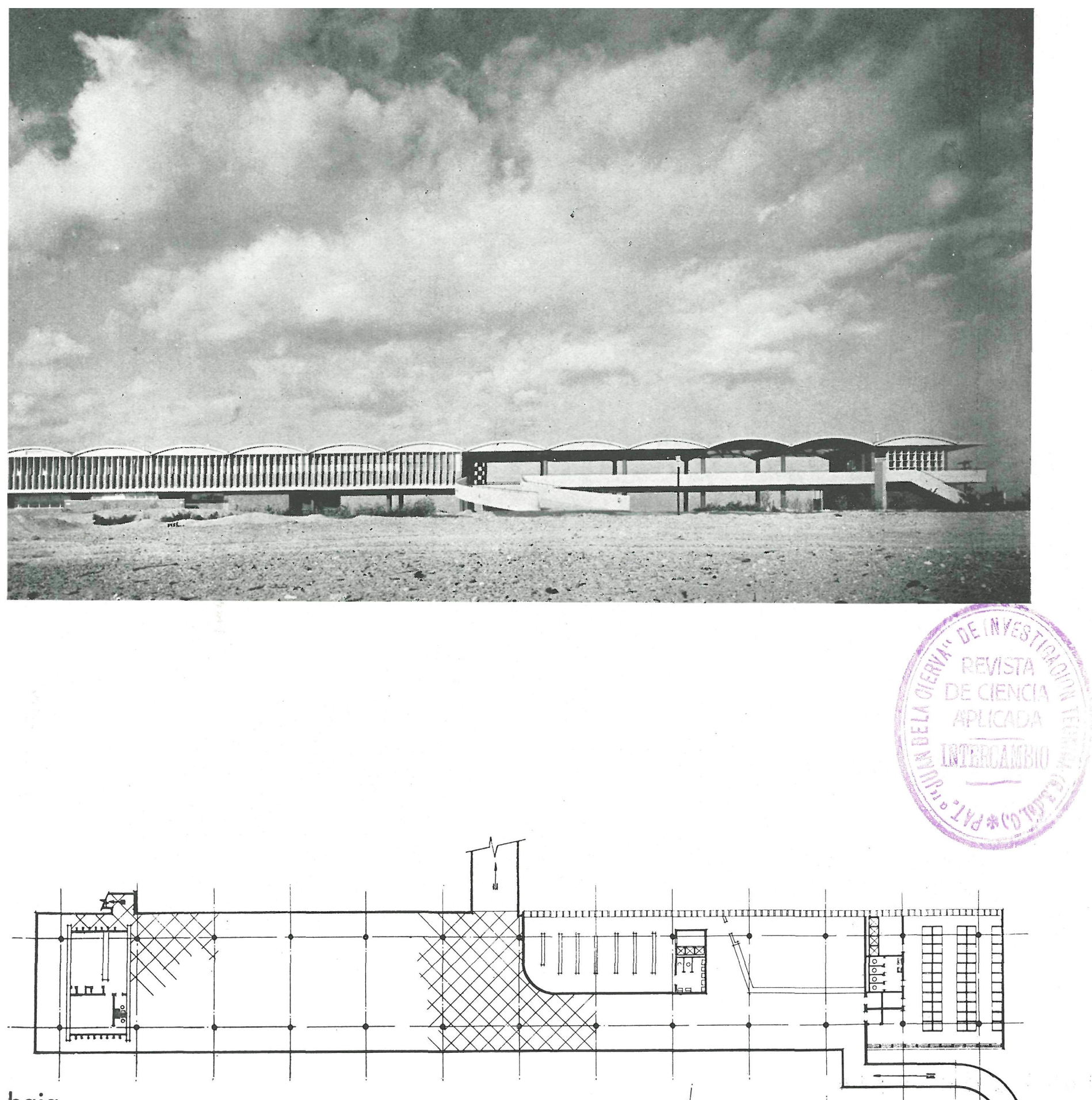

baja
primera
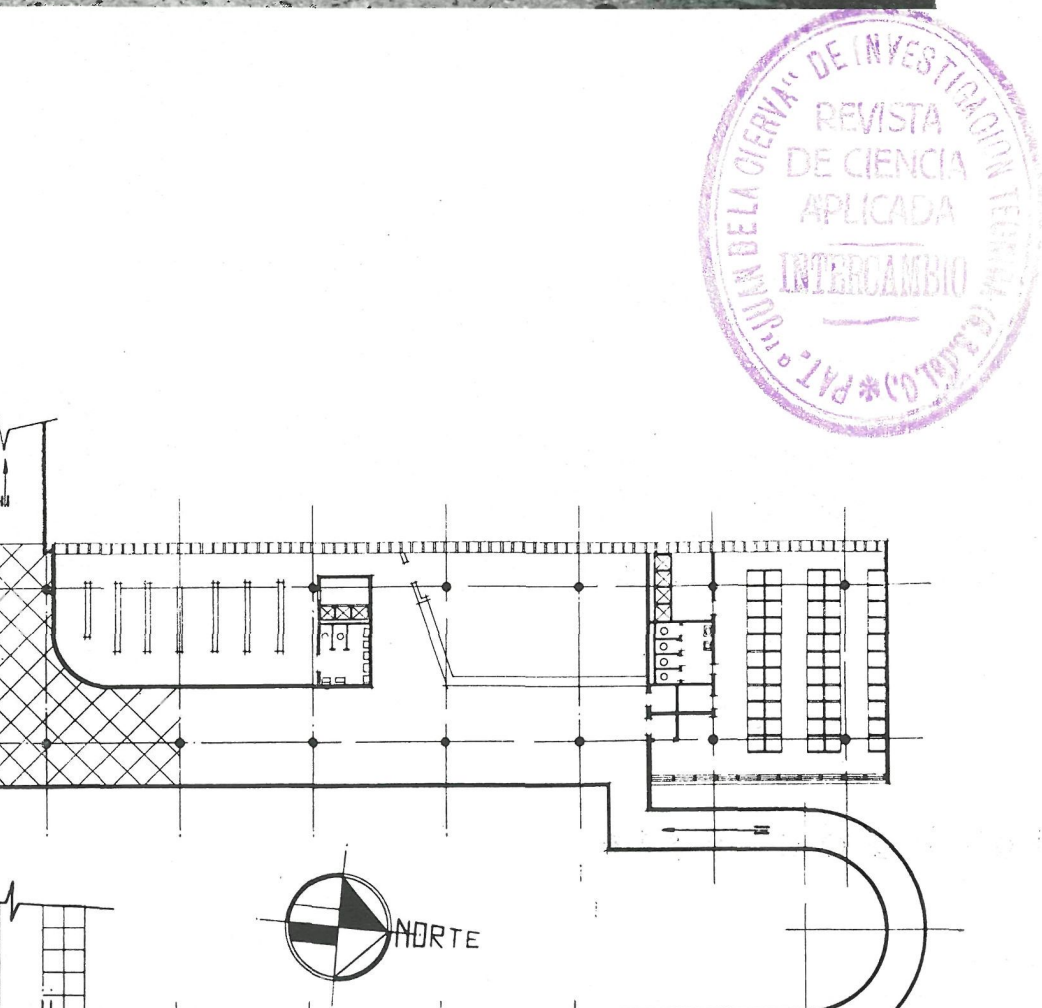


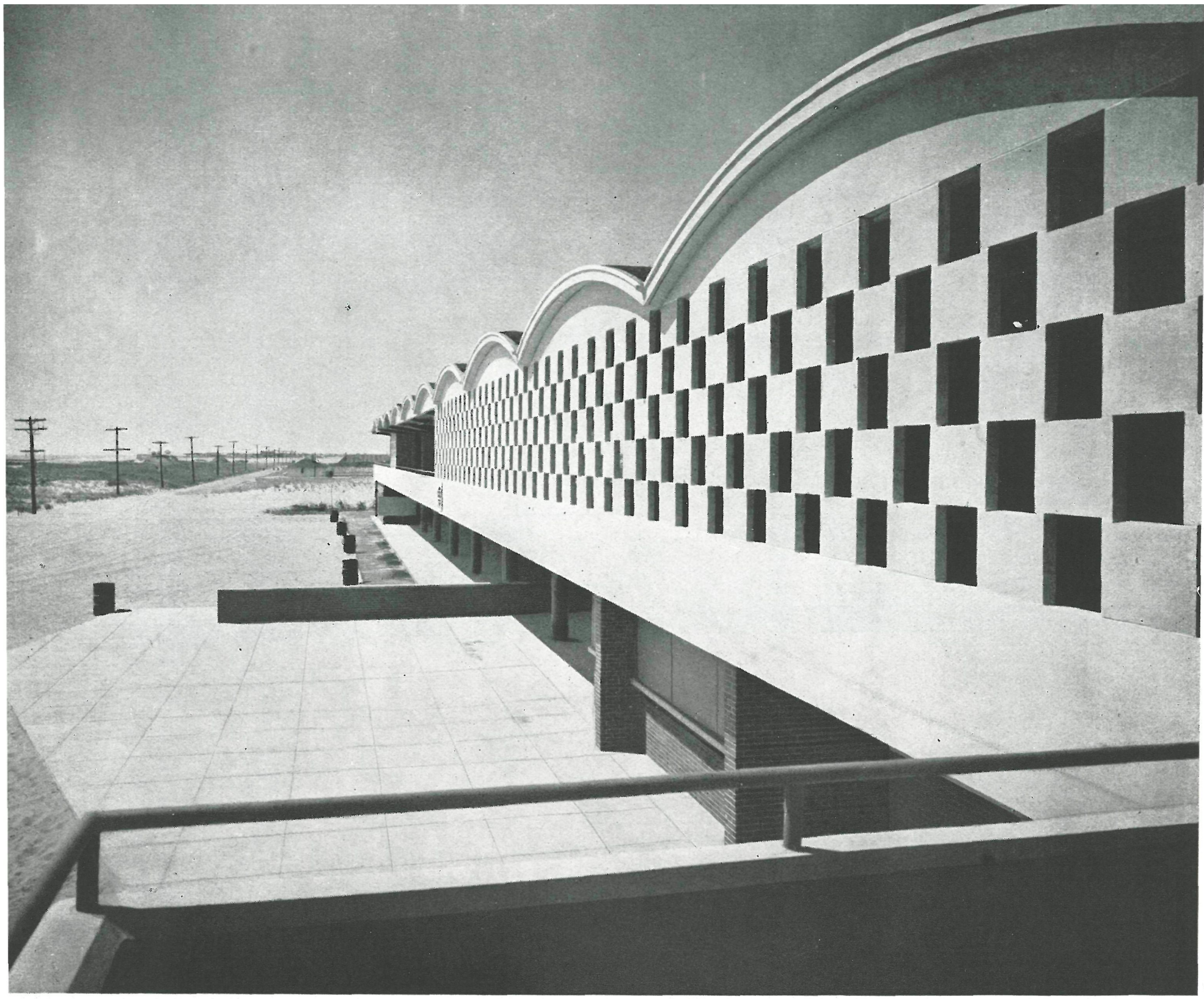

fachada este

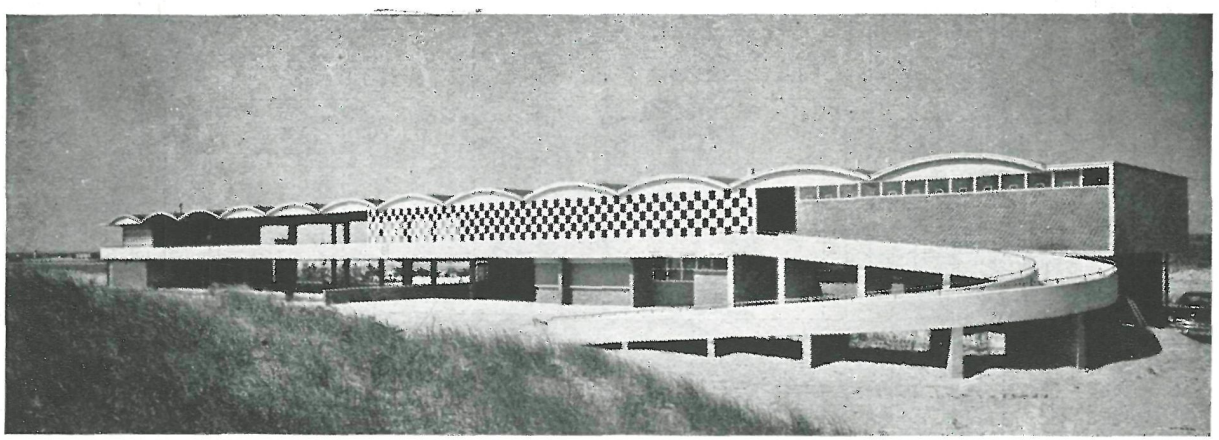

El material elegido ha sido el hormigón armado, a causa de su resistencia a la acción corrosiva de los vientos marinos y por su propiedad de admitir un tratamiento más plástico que otros materiales. El edificio se levanta sobre pilotes, para permitir la visión del mar a la gente que acude por la del mar a la gente que acude por la cuentra ante el espectáculo siempre bello y policromo de un fondo azul sobre el que destacan los colores vivos de los barcos y la blancura de las velas. En la primera planta se ha instalado una amplia terraza, que permitirá gozar del magnífico panorama y de las suaves brisas marinas sin exponerse a los despiadados rayos del sol. Una parte de la cubierta ondulada-precisamente la que corresponde a la terraza - se ha dejado descubierta para permitir la visión del cielo.
I NST I T U T O
TECN ICO
DE L A
CONSTRU
$C \subset I O N$ Y
D E L
C E M ENTO 


\section{fachada este}
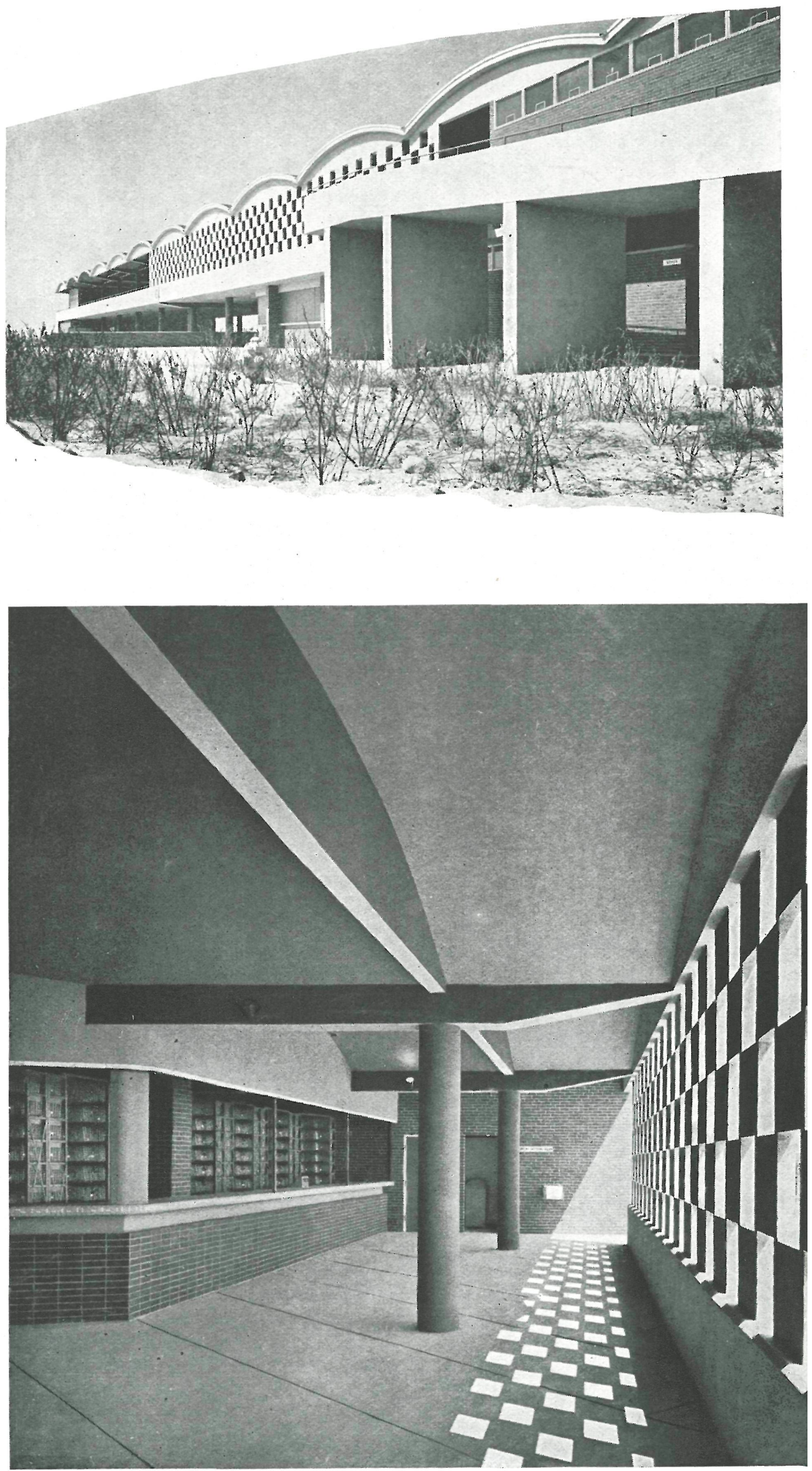

El cerramiento ajedrezado, en celosía de hormigón refuerza el carácter de ligereza y sencillez del conjunto.
I NFOR ME 

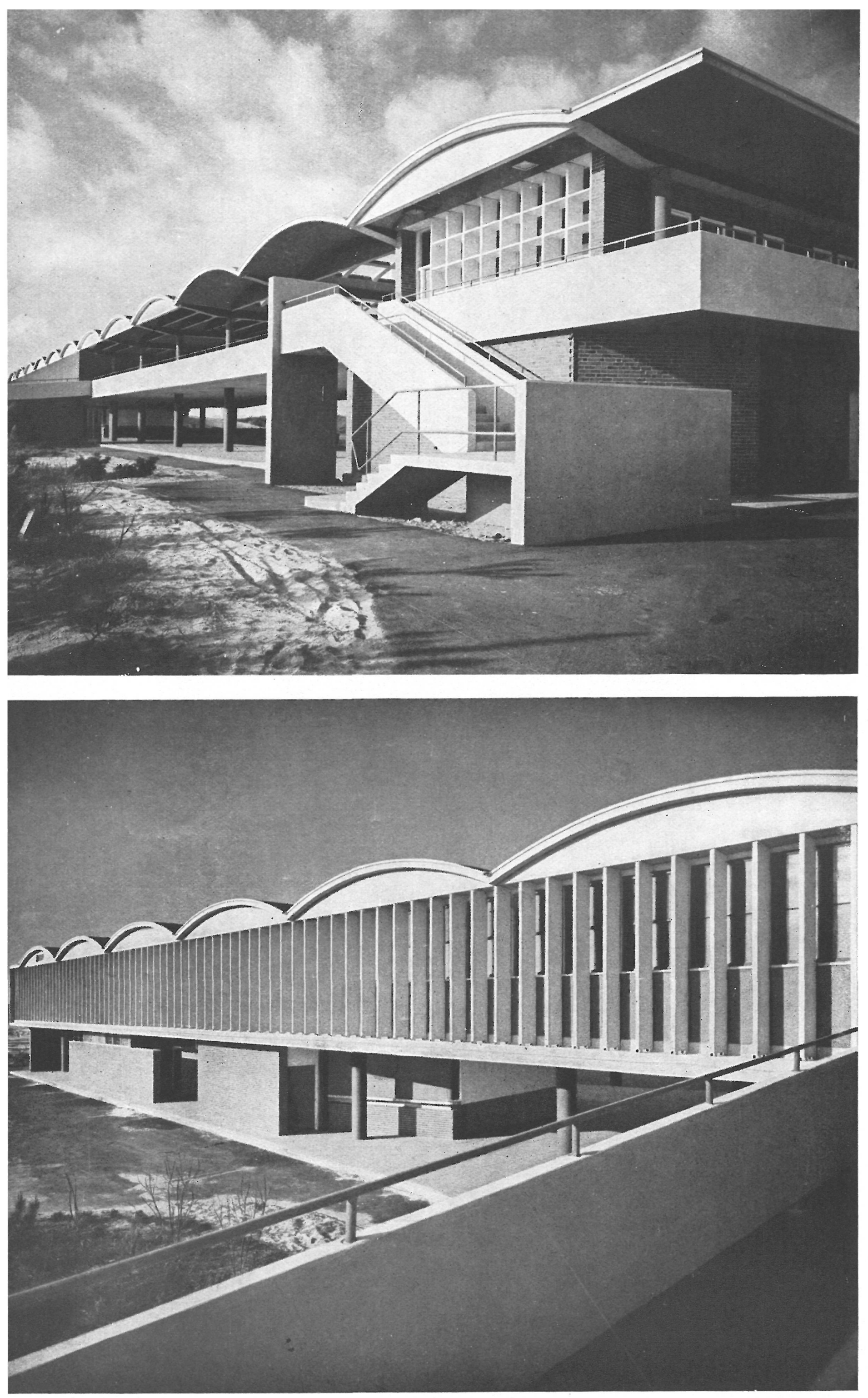

Fotos: J. W. MOLITOR.

Los dos principales problemas que se han presentado aquí, y que se han resuelto con sencillez $y$ funcionalmente, han sido los de circulación $\mathrm{y} v$ istas abiertas. El primero se ha solventado con dos rampas, una de entrada por la parte oeste y otra de salida, lo que permite el acceso a los vestuarios y salida a la playa sin cruzarse con los que, ya vestidos, pasen directamente hacia el mar por la parte abierta de la planta inferior.

A causa del clima reinante en la zona, fué necesario colocar una capa de hormigón asfáltico sobre la cubierta.

Se ha previsto la necesaria zona de aparcamiento y una oficina de portazgo, como cosas necesarias para completar el programa.

Los cerramientos, en las partes que han sido necesarios, son variados y prestan gracia a tan sencillo edificio. Las partes blancas y ciegas de los laterales se combinan con el ajedrezado de la fachada oriental y algunas zonas de ladrillo visto.

Podemos decir, en definitiva, que se ha sacado el máximo partido al lugar y a las exigencias del programa, destacándose la construcción por su sencillez de líneas sobre la dramática desnudez del terreno.

\footnotetext{
fachada oeste
} 